\title{
Party System Compactness: Measurement and Consequences
}

\author{
R. Michael Alvarez \\ Division of Humanities and Social Sciences, Mail Code 228-77, \\ California Institute of Technology, Pasadena, CA 91125 \\ e-mail:rma@hss.caltech.edu \\ Jonathan Nagler \\ Department of Politics, New York University, 726 Broadway, \\ Room 752, New York, NY 10003 \\ e-mail: jonathan.nagler@nyu.edu
}

\begin{abstract}
An important property of any party system is the set of choices it presents to the electorate. In this paper we analyze the distribution of parties relative to voters in the multidimensional issue space and introduce two measures of the dispersion of the parties in the issue space relative to the voters, which we call measures of the compactness of the parties in the issue space. We show how compactness is easily computed using standard survey items found on national election surveys. Because we study the spacing of the parties relative to the distribution of the voters, we produce metric-free measures of compactness of the party system. The measures can be used to compare party systems across issues, over time within countries, and across countries. Comparing the compactness of party systems across countries allows us to determine the relative amount of issue choice afforded voters in different polities. We examine the compactness of the issue space and test the impact it has on voter choice in four countries: the United States, the Netherlands, Canada, and Great Britain. We demonstrate that the more compact the distribution of the parties in the issue space on any given issue, the less voters weight that issue in their vote decision. Thus we provide evidence supporting theories suggesting that the greater the choice offered by the parties in an election, the more likely it is that issue voting will play a major role in that election.
\end{abstract}

\section{Introduction}

That voters evaluate where candidates or parties stand on issues has become accepted wisdom in theories of elections, and measures of the relative positioning of voters and parties are now common in empirical analyses of elections (Downs 1957; Davis and Hinich

\footnotetext{
Authors' note: Previous versions of this paper have been presented at the Spring 1998 meeting of the Southern California Political Methodology Program, May 1998, San Diego, CA; the 1998 meeting of the Midwest Political Science Association, April 1998, Chicago, IL; and the 1998 meeting of the Western Political Science Association, March 1998, Los Angeles, CA. We thank Jennifer R. Willette for her research on this project, Matt Golder for his comments, and the reviewers of Political Analysis for their very helpful and thought-provoking comments. Alvarez's work was supported by the National Science Foundation through SBR-9709327 and the IBM Corporation's University Matching Grants Program; Nagler's work was supported by the National Science Foundation through SBR-9413939 and SBR-9709214.
}

Political Analysis, Vol. 12 No. 1, (C) Society for Political Methodology 2004; all rights reserved. 
1966; Davis et al. 1970; Enelow and Hinich 1984; Alvarez and Nagler 1995, 1998a, b; Alvarez 1998). There is also a long tradition in political science of emphasizing whether or not candidates or parties are actually offering voters choices (rather than echoes) on issues (Downs 1957; Key 1966; Page and Brody 1972; Shepsle 1972; Page 1976, 1978; Bartels 1986; Brady and Ansolabehere 1989; Franklin 1991; Alvarez and Franklin 1994; Alvarez 1998). This paper is based on a straightforward theory: voters should weight issues most heavily when there are clear differences between the parties on the issues. If parties offer no real alternatives on a given issue, the voters' choice between the parties will have no effect on the expected policy outcome because the policy pursued is the same no matter which party wins the election. Voters presumably vote on issues when the success of one party over another will result in different policy outcomes. Thus the contributions of this paper are twofold. First, we develop measures of how great are the choices offered by parties that allow for cross-national comparison of party systems. Our measures of the choices offered by the party system are unique in that they are the only measures in the literature that evaluate the dispersion of the parties relative to the voters. Second, we use these measures to demonstrate the validity of our theory in a cross-national context.

This simple and straightforward theory is based on a long tradition of research on voting in American national elections. Key (1966, p. 2) asserted this theory with his "echo chamber" analogy:

\begin{abstract}
The voice of the people is but an echo. The output of an echo chamber bears an inevitable and invariable relation to the input. As candidates and parties clamor for attention and vie for popular support, the people's verdict can be no more than a selective reflection from among the alternatives and outlooks presented to them.
\end{abstract}

Subsequent research focused attention on studying one aspect of Key's "echo chamber" argument: how the clarity with which candidates and parties articulated their policy positions influences voter ability to choose between candidates and parties on the basis of issues (Page 1976, 1978; Bartels 1986; Alvarez and Franklin 1994; Alvarez 1998). Here we look at another equally important aspect of Key's echo chamber model: the amount of choice given to voters from the diversity of issue positions offered by candidates and parties.

Consider voters motivated by only two factors: the state of the economy and a policy issue. If voters are asked to choose between two parties that offer identical positions on the policy issue but have different records on the economy, then it seems clear that any empirical investigation of voter behavior could not reveal that voters use the policy issue to choose between the two parties. Voters have no way to reveal their preferences about the policy issue, so in this example voters cannot use the policy issue in their decisions and must resort to alternative selection criteria. ${ }^{1}$ If they are going to vote, they must choose from among the available parties using information about the economic differences between the parties (in this example).

Testing this theory requires two steps. First, we must be able to distinguish issues on which the parties differ substantially from issues on which the parties offer very similar positions. Second, we must also observe how heavily voters weight each issue. In this paper we address the problem of measuring whether parties offer choices or echoes, in a way that is comparable across countries. To do this we develop two measures of the compactness of the parties in the issue space relative to the voters. We then examine

\footnotetext{
${ }^{1}$ A similar argument is advanced in Alvarez (1998), but there he was concerned with how the effects of voter uncertainty on issues would make it difficult for voters to use issues in their voting decisions. He found strong support for this proposition in a number of recent American presidential elections.
} 
whether voters weight issues more when the parties are more dispersed in the issue space and are offering clearer choices. We do this by estimating a random utility model of voter choice and comparing the coefficients on the issues-measures of the weights voters place on the issues in making their vote choice-to the compactness measures of the party space on the issue. Analyzing survey data from recent elections in four countries-the United States, Canada, Great Britain, and the Netherlands-we show that the more dispersed the parties are in the issue space relative to the voters, the greater weight the voters place on the issue in making their choice. This is confirmation of our theoretical argument that voters can use issues in their decisions only if the parties have presented distinctive platforms to the electorate.

\section{Measuring Party System Compactness}

In this section we develop measures of party issue space compactness that are comparable across elections and nations. Comparability across nations is critical, as it is a common refrain that parties in the United States do not offer distinct choices but that parties in West European parliamentary systems do. Yet to verify this stylized fact we need to measure the gap between the parties in the issue space in a way that is comparable across issues and across countries. We develop such measures relative to the preferences of the voters. Specifically, we develop measures of the dispersion of parties in the issue space relative to the dispersion of voters in the same issue space.

If voters are widely distributed on an issue, such that many have views far to the left of center and many have views far to the right of center, then the parties must be reasonably far apart from each other to offer meaningful choices to the voters. If voters are tightly distributed on an issue, then the parties could also be tightly distributed yet offer meaningful choices to the voters. We refer to the dispersion of the voters relative to the dispersion of the parties as the compactness of the parties in the issue space. ${ }^{2}$

Our definition of compactness is explicitly a measure of the dispersion of the parties relative to the voters, not a measure of the dispersion of just the parties on some abstract scale. This helps deal with a fundamental problem in survey research, namely, that respondents do not perceive the questions or the scale in the same way. This problem has been noted in the political science literature for decades (see, for example, Aldrich and McKelvey 1977 and Palfrey and Poole 1987, and more recently Poole 1998). Two respondents with identical political preferences might place themselves at different points on an issue scale. Similarly, two respondents with identical beliefs about a given political party may place the party at different points on an issue scale. For instance, voter A may believe that abortion on demand should be state policy as long as it is within the first trimester, and voter B may believe that abortion should be legal only in cases of rape, incest, or danger to the mother, yet they may both place themselves at 4 on a 7-point scale on abortion rights. In other fields, this is referred to as differential item functioning (see Holland and Wainer 1993 for discussion of these literatures). If we are to compare the level of choice given to voters, we need to know how much choice the voters themselves believe they have.

An obvious alternative is to measure in an absolute way where the parties are in the issue space and have that be comparable across countries. This is the approach that King

\footnotetext{
${ }^{2}$ We frequently use the shorthand "compactness of the issue space" to indicate the compactness of the parties in the issue space relative to the voters. Below we develop two different operationalizations of this concept; one we call the "basic" measure of compactness, the other the "vote-weighted" measure of compactness.
} 
et al. (2003) take in their work on vignettes. They attempt to produce common anchors so that respondents' perceptions of events are comparable across countries. This same idea has been applied to the measurement of party positions by having a common set of experts place the parties across all the countries using objective data and identical coding rules (this is the work of the Comparative Manifestos Project, which we discuss in detail later). ${ }^{3}$ But this approach does not allow us to compare how far apart the voters in a given country see their parties as being, because the party manifesto data do not include any information from voters about their issue positions or their perceptions of party issue locations.

Imagine that we measure "liberalness" on a 7-point scale. Our experts assert that the right party is at 6 and the left party is at 2 in country A, while in country B the right party is at 5 and the left party is at 3 . Does this imply that country A offers the voters more choice than country B? There are two ways to answer this question, depending on whether we look at a single voter in each of the countries or at the set of voters in each country. If we looked at a single voter in each country, it would appear that country A offers a more diverse party space than country B. But what would it mean if in country B the voters are clustered between 3.9 and 4.1, while in country A the voters are distributed uniformly between 1 and 7? In this situation, we would not know if the greater dispersion of voters in country A versus country B were due to differential item functioning or to the presence of more variance in the distribution of preferences in country A versus B. So if we wanted to know in which country the parties were more dispersed relative to the voters, we would have to use our measure, which explicitly allows voters in each country to place their own parties.

We now specify how we calculate our measure. Consider a polity with $J$ parties and $K$ issues. We denote the placement of the $j^{t h}$ party on the $k^{\text {th }}$ issue as $P_{j k}$. Thus we can tell precisely how far apart any two parties $j$ and $l$ are on an issue $k$ by simply examining the absolute distance between them: $\left|P_{j k}-P_{l k}\right|$. However, as we discussed above, this quantity is not based on a metric that will ultimately allow for comparisons across countries. To interpret how far apart the parties are, we need something to compare them to. One important point of reference is the dispersion of the voters in the issue space, which can be measured by examining the distribution of the voters on each issue. The standard deviation of respondents' self-reported positions on the issue, which we denote on the $k^{\text {th }}$ issue by $\sigma_{k}$, represents the dispersion of the voters. The larger the value of $\sigma_{k}$, the more dispersed the voters are on issue $k$. We then compute one measure of the compactness of the party space on issue $k$ as

$$
C P_{k}=\frac{\sigma_{k}}{\max \left|\left(P_{j k}-P_{l k}\right)\right|} \quad \forall j, l
$$

We call this the basic measure of compactness. ${ }^{4}$

The larger the value of $C P_{k}$, the greater the ratio of dispersion of the voters to the dispersion of the parties. In other words, a high value of $C P_{k}$ indicates that voters place themselves across a wide range of the issue space but the parties are clustered in a very narrow range of the issue space. This suggests a limited set of alternatives for the voters, so we refer to this as a "compact" issue space. Conversely, if $C P_{k}$ had a low value, it would

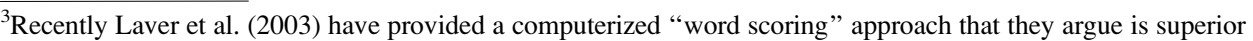
to the use of "experts" to content analyze party manifestos. Interestingly, their comparative analysis of their technique relative to expert coding shows little difference (see Fig. 2 of their paper, pp. 324-325).

${ }^{4}$ Van Der Eijk (2001) offers an alternative measure of dispersion to the standard deviation, which he criticizes for measuring skew and dispersion.
} 
indicate that the voters are not spread out very much relative to the parties from which they choose. Finally, note that we are measuring compactness on an issue-by-issue basis because parties may be dispersed on some issues but compact on others.

This compactness measure is based on the maximum distance between any two parties; we do not attempt to weight the distance between those two parties based on vote share of the parties or any measure of the strength of each party. This is a potential problem with the measure because the existence of a minor party far from any other party will alter the compactness measure, even if the minor party controls no seats in the legislature and is not considered by voters to be a viable alternative. Thus our second measure of compactness is related to the first, but takes into account the vote shares of the major parties in each election and the relative positions of all viable parties in the issue space (relative to the vote-share-weighted global mean for the parties on the issue). We call this measure voteweighted compactness to differentiate it from the basic measure of compactness.

The intuition behind the measurement of vote-weighted compactness is straightforward. We begin by computing the weighted mean of the parties in the issue space (with the weights being each party's fraction of the vote in the current election), then weight the contribution of the distance from each party to this weighted mean by the vote share of the party. The calculation of vote-weighted compactness is given by

$$
V W C P_{k}=\frac{\sigma_{k}}{\sum_{j=1}^{N} V_{j}\left|\left(P_{j k}-\bar{P}_{k}\right)\right|},
$$

where

- $\bar{P}_{k}=$ the weighted mean of parties on the issue, where each party is weighted by vote share.

- $V_{j}=$ the $j^{\text {th }}$ party's share of the vote.

Thus while the numerators of both measures of compactness are identical-meaning that the reference point for measuring compactness in either case is the distribution of voters on different issues - the denominators of the two measures are quite distinct. We explore in subsequent sections the empirical performance of both measures of compactness.

Fortunately, measures of all the quantities needed to compute compactness and voteweighted compactness are available from many existing national election surveys. In national election surveys the positions of respondents on the issues are frequently measured by the use of issue scales. The standard methodology is to identify an issue for respondents, show them a number line ranging from 1 to 7 (or 1 to 11 ), describe the meaning of at least the endpoints on the number line (and perhaps the midpoint of the line), and ask the respondents to place themselves on the number line. The standard deviation of these placements on any issues gives us a measure of $\sigma_{k}$. Respondents are also often asked to place the parties, or candidates, on these issues. The mean placement of the party can be used as an estimate of the actual placement of the party in the issue space, $P_{j k}{ }^{5}$

\footnotetext{
${ }^{5}$ We estimate our compactness measure using only the placement of the parties offered by highly educated respondents, who are defined as the top two-fifths of respondents. This is driven by research by Alvarez and Franklin (1994) showing that uninformed respondents (here we assume that uneducated voters are more likely to be uninformed) will tend to place a party at the middle of the issue scale, rather than reporting no opinion. In a sample with a large proportion of such uninformed voters, placements of all parties will converge towards the middle of the issue scale, hiding true variation among party positions.
} 

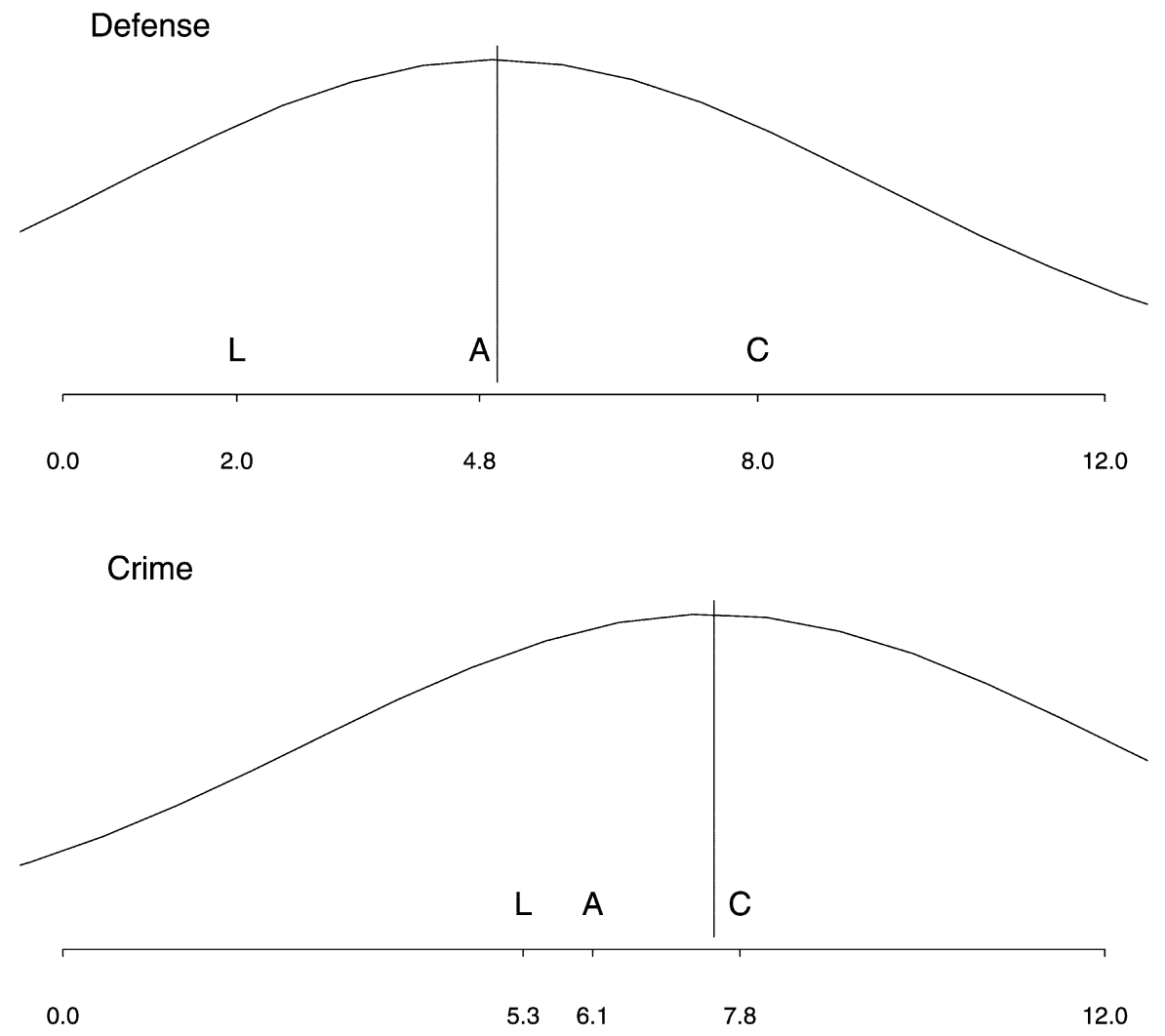

Fig. 1 United Kingdom issue space compactness measurement example. In both panels of the figure, the relative positions of the three parties (Liberals, the Alliance, and the Conservatives) are given by the letters $\mathrm{L}, \mathrm{A}$, and $\mathrm{C}$, respectively. The vertical line in each panel gives the average voter position on each issue. The top panel provides an example using the defense issue, using 1987 data from the United Kingdom; voter mean is 5.0, standard deviation 2.4. The basic compactness measure is 0.4 , the vote-weighted measure is 1.01 . The bottom panel gives an example using the crime issue, again using 1987 United Kingdom data; here the voter mean is 7.5, standard deviation 2.6. The basic compactness measure for the crime issue in the lower panel is 1.08 , the vote-weighted measure in the lower panel is 2.56 .

We provide an illustration of our two compactness measures in Fig. 1. Using actual data from the 1987 British Election Study, we show the compactness of the issue space for two issues: defense and crime. ${ }^{6}$ In the top panel of Fig. 1 we represent the distribution of voter positions on defense as a symmetric distribution, with a mean of 5.0 and a standard deviation of 2.4 (which are the actual mean and standard deviation in the survey sample). On the horizontal axis, we present the position of Labour (2.0), the Alliance (4.8), and the Conservatives (8.0). Each party's position is estimated from the British Election Study data. For the issue of defense, it is clear that the parties are widely dispersed in the issue space, with the absolute distance between the two extreme parties (Labour and

\footnotetext{
${ }^{6} \mathrm{We}$ will report on the estimation of the compactness measure in much more detail below. Here we are using this as an example to provide intuition for our compactness measure. We use a symmetric distribution for the voter positions only for convenience, because the distributions of voter positions that we provide in Fig. 1 are hypothetical.
} 
Conservative) being 6.0 points on this issue scale. Thus basic compactness is quite low for this issue (.4).

When we compute vote-weighted compactness, though, we take into account the relative distance of each party to the vote-share-weighted global mean and weight this by the vote share; this quantity becomes the denominator in the computation of vote-weighted compactness (with $\sigma_{k}$ being the numerator). As the Conservatives received 42.3\%, Labour $30.8 \%$, and the Alliance $22.5 \%$, we use those as weights in the computation. We produce an estimate of 1.01 for vote-weighted compactness on the defense issue.

In the lower panel of Fig. 1 we present the crime issue. Again, we give the distribution of voter positions on this issue using a symmetric distribution, with mean 7.5 and standard deviation 2.6 (again, these are the actual mean and standard deviation from the survey data). So despite the fact that the central tendency of the voter distribution on crime is more conservative than on defense, the standard deviations of voter positions are almost identical in both examples. It is the standard deviation that is important in our compactness measure, and the standard deviation is virtually constant in the two examples. The only really important difference between the examples is where the parties are located on each issue, which is given on the horizontal axis for Labour (5.3), the Alliance (6.1), and the Conservatives (7.8). On the crime issue, the party positions are quite compact because the distance between the extreme parties is quite small relative to the distribution of the voters. The basic compactness measure here is quite high (1.08), indicative of the much more compact issue space than on the issue of defense. Likewise, we compute vote-weighted compactness for the crime issue. Again, taking the vote shares of the three parties into account and the relative distances between each party and the vote-weighted global mean on the issue, we obtain an estimate of vote-weighted compactness of 2.98 for the crime issue.

This simple example shows how both measures of party system compactness work. In Fig. 1 it is clear that the relative spread of the British electorate on each issue is almost identical, but what is changing between the two issues is the relative spread of the party positions. Crime is an issue on which the British parties in 1987 were much more similar than the defense issue, and that is reflected in both compactness measures. The fact that the vote-weighted measure in this example does not radically differ from the basic measure is due to the fact that the vote shares are relatively evenly distributed across the parties (the Conservatives received $42.3 \%$ of the vote, Labour $30.8 \%$, and the Alliance $22.5 \%$ ) and because none of the three parties are significant outliers on either issue. For example, had the Conservative party received more than $50 \%$ of the vote in this election and taken an even more conservative stance on the defense issue, we would see a much greater voteweighted compactness score and much more difference between the two compactness measures.

Our measures of party system compactness are distinct from those previously advanced in the literature in a number of important ways. Most important, our measure allows for meaningful comparisons across countries of how far apart parties are relative to voters within the party system. One early and prominent example of a metric of party issue space positioning was offered by Sartori (1976) in his two-dimensional classification scheme of party systems; Sartori's scheme is the first to focus on party ideological distance in the literature on party systems (Mair 1996). Sartori argued that there are two important dimensions: party fragmentation (the number and relative size of parties in national legislatures) and ideological distance (the ideological distance of parties in the left-right space and the general orientations of the various political parties to the nation's political system). 
There have been various attempts to operationalize Sartori's ideological distance dimension. One recent example is Ware's (1996) study, in which he operationalizes ideological distance for 19 countries by the ideological distance between the most extreme of the large parties in the nation's party system, using the Laver and Hunt (1992) expert survey data for the ideological positions of the extreme parties. ${ }^{7}$ This approach to measuring party spatial competition is limited in that it ignores the relative locations of voters in the left-right space, and because it does not allow for analysis of multiple issues and instead focuses exclusively on one ideological dimension. If we were interested in comparing the space between parties on some absolute scale this measure would obviously be more appropriate than what we propose. However, as we wish to compare the degree of choice offered to voters across party systems, this measure is inappropriate.

Another measure of spatial competition was offered by Bartolini and Mair (1990). Their measure is based on data collected by Budge et al. (1987) from party economic policy platforms in 11 nations for a four-decade period. Bartolini and Mair factor analyze the party platform data and come up with a measure of party positions in the left-right space by focusing on the primary factor estimated in their analysis. ${ }^{8}$ An important justification for the Bartolini and Mair measure is that the party platform data are available for a number of decades; however, despite that important feature of their measure, their analysis focuses on one dimension of the issue space (economic competition) that might be unrelated to spatial issue positioning. More important for our purpose, their measure also ignores the relative positioning of the parties to the electorate in the issue or ideological space.

A similar measure has been developed, using the same basic data source, by Klingemann and Wessels (2002, p. 6), who called their measure "political polarization." They describe their measure: "Positions of parties on the left-right dimension are measured by generalizing from positions on specific policies, such as promoting freedom or democracy, market- or state-economy, anti- or pro-welfare policies and foreign policies which either emphasize security by strong military defense, or alternatively, by security through peace and detente policies. The score representing policy differentiation (or polarization) was calculated by adding absolute distances on this left-right dimension between all possible pairs of parties and then standardizing this measure to the number of parties in the political system." This approach to measuring party polarization or differentiation, like the Bartolini and Mair approach, also ignores the relative positioning of the parties to the electorate.

Kim and Fording (2002) outline a methodology by which party manifesto estimates of party positions, combined with vote shares of the parties, can be used to produce estimates of the median voter position on ideology. But they estimate only the median voter, not the distribution of voters, and the technique is based on the heroic assumption that all voters choose the party closest to them on the issue. Because Kim and Fording are using a general ideology measure, this assumption is at least plausible. When using more specific issues this technique would be problematic.

In an earlier study, Klingemann (1995) did examine the relative positions of parties and voters in the left-right ideological space. However, in this paper Klingemann used the party manifesto approach (studying only domestic issues) to estimate party ideological positions, but then used Eurobarometer survey data for ten nations (with ideological

\footnotetext{
${ }^{7}$ See Ware (1996), Chapter 5, for further discussion of his analysis of Sartori's classification scheme.

${ }^{8}$ A similiar approach was used by Castles and Mair (1984), where they used an expert survey to estimate the party positions in the left-right space.
} 
positions being measured on a 10-point scale) and separate Swedish and Norweigan survey data (with ideological positions measured on a variety of different scales). While consistent with our argument that it is important to measure the relative differences between voters and parties in issue spaces, the fact that different data sources are used to estimate party and voter positions raises the differential item functioning problem in a critical way: experts and voters are unlikely to see the issue space identically.

However, the use of the party manifesto data to estimate left-right ideological placements for political parties has been critized by Gabel and Huber (2000). They demonstrate that the empirical explanatory power of ideological placements of parties using manifesto data is sensitive to pooling assumptions and to the particular estimation technique. Gabel and Huber do include one of Klingemann's (1995) approaches in their study of four different methods and find that it performs qualitatively worse than two of the other approaches they study. However, the measure discussed for ideological placement in Klingemann (1995) does appear to differ somewhat from that in Klingemann and Wessels (2002), primarily because the latter includes foreign policy in the measurement of left-right ideology. As a secondary concern, it is also important to note that the party manifesto approaches to the measurement of ideological positioning use some form of factor analysis in the first stage to reduce the estimated party positions on a multitude of issues to a single dimension. This implies that there are two sources of statistical uncertainty contained in the estimates of party positions in the left-right space: uncertainty from the original expert coding and uncertainty from the statistical estimation. Only one study that we have found takes this uncertainty into account when using the leftright estimates of party positions in second-stage statistical analysis, thus raising the possibility that virtually all of the other second-stage analyses reported in the literature to date might have incorrectly estimated the variance of the second-stage estimates (see Laver et al. 2003.)

One interesting study, using survey data, has focused on the positioning of the electorate, rather than the parties themselves, in the ideological space: Sani and Sartori's (1983) article on party system polarization. They study 11 nations, using 1976 Eurobarometer data, and come up with rough estimates of party positions in the leftright space using the self-placements of party members. Using these estimates, they develop three innovative measures of party system polarization-partisan overlap, ordinal similarity, and pairwise ideological partisan distances (p. 321). While innovative for their use of the positions of voters in the left-right space and for the definition of the three dimensions of party polarization, the Sani and Sartori measure is based on an important assumption needed to draw inferences about party positions: that partisan members have personal ideological placements that represent their parties accurately. If this assumption holds, the Sani and Sartori measures should be accurate indicators of ideological competition; if not, and if parties have positions at variance with their self-proclaimed members, their measure will be biased in an unknown direction. While the Sani and Sartori measure captures an important aspect of the electorate, it is distinct from what we attempt to capture with our measure: the relative dispersion of parties relative to voters in the issue space.

Thus our party system compactness measures differ in important ways from the operationalizations that have been prominent in past research. Our measures include information about the positions of both the parties and the voters, whereas past research has tended to focus on only the relative positions of the parties (the Sani and Sartori study being an important contrast here). Our measures also allow for the analysis of multiple issue spaces, or simply the ideological left-right dimension, depending on the availability of issue 
placement questions in national election surveys. Finally, with the widespread availability of national election surveys for many countries now spanning decades, there is a plethora of data available for the operationalization and analysis of our party compactness measures.

In the following section we report the compactness of the party space for each of four countries: the United States, Canada, the United Kingdom, and the Netherlands. We have selected these four cases since they vary on different political and social attributes, which we discuss in more detail below. These four cases are also ones for which we have excellent voter opinion data, especially since each national election study includes a number of different issue placement questions for the different candidates or parties. For each of the countries in our sample we report detailed party system compactness estimates for recent elections. For the United States we use the 1996 presidential election; for Canada we use the 1993 parliamentary election; for the United Kingdom we use the 1987 parliamentary election; and for the Netherlands we use the 1994 parliamentary election. Following the presentation of the compactness measures for each country, we examine the relationship between compactness and issue voting through multivariate models of issue voting.

\section{Measurement of Compactness in Each Nation}

For the United States we analyze the 1996 American National Election Studies (NES) (Rosenstone et al. 2000). In the 1996 NES, respondents were asked to place themselves, Clinton, Dole, and Perot on six 7-point scales for ideology and issues (spending on government services, defense spending, government jobs, aid to blacks, approaches to crime reduction, and environmental regulation). Positions one and seven on each issue scale are the extreme positions specifically defined in the survey questions, but the middle positions are not specifically defined. The ideological placement differs, because the survey question offers the respondent seven defined responses (extremely liberal, liberal, slightly liberal, moderate, slightly conservative, conservative, extremely conservative).

Our analysis of the 1993 Canadian election is very similar, using the 1993 Canadian Elections Study (CES) (Johnston et al. 1995). In the 1993 study, respondents were asked to place themselves and four parties on six issues: status of Quebec, Canadian ties to the United States, the role of the government in helping business, the power of labor unions, the role of the government in helping women, and the role of the government in helping minorities. The CES data set gives the respondent five specifically defined responses for each of our six issues. Positions one and five represent the extreme positions, with three defining an "about the same" option. For example, one question offers five response options as to how close the respondent would like Canada's ties with the United States to be: much closer, somewhat closer, about the same, more distant, and much more distant. $^{9}$

We analyzed the 1987 British Election Study (BES) for the United Kingdom (Heath et al. 1995). In the 1987 BES, respondents were asked to place themselves and the parties on seven issues: defense, Phillips Curve, taxation, nationalization, redistribution, crime, and welfare. The 1987 British Election Study uses an 11-point scale for each of our seven issue questions. Positions one and eleven represent the extreme positions, which are defined in the survey question. The middle positions are not specifically defined, but the

\footnotetext{
${ }^{9} \mathrm{We}$ treat these responses as if they are responses to standard scale questions.
} 
question suggests that position six is the center of the scale. ${ }^{10}$ In our vote-choice model we include variables for respondent perceptions of changes in inflation, taxes, and unemployment. We control for region of residence, union affiliation, occupation, gender, age, homeownership, income, and education. This is identical to the systemic specification employed in Alvarez and Nagler (1998a).

Finally, we analyzed the 1994 Dutch Parliamentary Election Study (DPES) (Anker and Oppenhuis 1997). In the 1994 DPES, respondents were asked to place themselves and each of four parties on seven issues: euthanasia, crime, income differences, nuclear power, ethnic minorities, European integration, and ideology. The 1994 DPES uses a 7-point scale for each of the seven issue questions. One and seven represent the extreme positions specifically defined by the question, but the middle positions are not defined. Ideology is measured differently because they use a 10-point scale with the extreme positions defined as left (1) and right (10). The middle positions are not defined.

\section{Compactness and Issue Voting}

In this section we examine one important behavioral implication of issue compactnessour expectation that voters will be less likely to be able to vote on issues on which the parties take convergent positions, thus producing a compact issue space. Our hypothesis is that voters should not use issues on which the parties have taken highly compact and convergent positions in their decision-making calculus, since highly compact issues do not give voters the ability to differentiate between parties. However, issue spaces that are not compact should form the basis for voter decision making, since noncompact issues provide voters with ways to see clear and important differences between the various political parties.

To gain an intuition for how the compactness of the issue space should influence the ability of voters to use a particular issue in their decision making, consider the standard arguments about the clarity of party positions on issues (Key 1966). If parties take divergent stands on an issue (hence the issue space is not compact), two things are likely to happen. First, since the parties are probably taking these divergent stands because they believe this behavior will win votes, they will be quite likely try to communicate their divergent stands to the electorate. Second, due to the efforts by parties to inform voters about their positions, voters are likely to be informed about where the parties stand on the issue. Thus, with voters well informed about the divergent party positions, this increases the potential importance of the issue in any voter's calculus about which party most closely matches their own interests.

But if parties take virtually identical stands on an issue (hence the issue space is very compact), then they are not likely to spend their energies communicating this position to voters. There is little electoral gain to be had by campaigning on an issue on which your position is identical to that taken by the other parties, since that does not give potential supporters of other parties a compelling reason to vote for your party. So when the issue space is compact, there is likely to be little campaign discussion of this issue; with little information about the party positions on this issue, voters will be uncertain of the positions of the parties and will not rely upon this issue in their voting calculations.

\footnotetext{
${ }^{10}$ In the 1992 survey instrument we use for a comparison over time, five of the issues were asked using the same 11-point scale used in the 1987 study (Phillips Curve, taxation, nationalization, redistribution, and the European Community), but three of the issues were posed to respondents using a 7-point format (defense, welfare, and women's rights). Note that this does not change how the compactness calculation is performed.
} 
To test this we estimate a model of voting and examine the weight respondents place on the different issues. We specify a random utility model of voter choice, assuming that the respondent's utility is a function of choice-specific and individual-specific characteristics:

$$
U_{i j}=A_{i} \psi_{j}+X_{i j} \beta+\epsilon_{i j}
$$

where:

$U_{i j}=$ utility of the $i^{t h}$ voter for the $j^{\text {th }}$ party

$A_{i}=$ characteristics of the $i^{\text {th }}$ voter

$X_{i j}=$ characteristics of the $j^{\text {th }}$ party relative to the $i^{\text {th }}$ voter

$\psi_{j}=$ a vector of parameters relating the characteristics of a voter to the voter's utility for the $j^{\text {th }}$ party

$\beta=$ a vector of parameters relating the relationship between the voter and the party $\left(X_{i j}\right)$ to the voter's utility for the party

$\epsilon_{i j}=$ random disturbance for the $i^{\text {th }}$ voter for the $j^{\text {th }}$ party.

We assume the disturbances are distributed as independent extreme-value random variables and estimate this model using conditional logit. We interpret the estimated coefficients for the issue distance variables as the relative weight placed on those issues. For instance, if we estimate a coefficient for environmental regulation twice as large as for crime reduction, we would infer that voters weight this issue twice as heavily. Or, for each unit a voter is further from the party on environmental regulation, they penalize the party twice as much as they do for the party being a unit further away on crime prevention.

We have estimated well-specified models of voter choice for one of the elections in each of the four nations (in the United States we use the 1996 presidential election, in Canada we use the 1993 election, in the United Kingdom we use the 1987 election, and for the Netherlands we use the 1994 election). In the vote choice model for the United States, we include variables for respondent perceptions of personal finances and the national economy, spending preferences for welfare and social security, and opinions on the proposed $15 \%$ tax cut, abortion, and government health insurance. In addition we control for education, partisan identification, gender, age, and region of residence. In our model for the 1993 Canadian election, we include variables for respondent perceptions of personal finances and the national economy and control for region of residence, gender, age, education, union affiliation, and income. The vote choice model for the 1987 British election includes variables for respondent perceptions of changes in inflation, taxes, and unemployment, as well as controls for region of residence, union affiliation, occupation, gender, age, home ownership, income, and education. In our vote choice model for the 1994 Dutch election, we include variables for respondent perceptions of the national economy, employment, and personal finances and controls for education, gender, age, union affiliation, and income. These specifications are identical to those found in previous research using these same cases (Alvarez and Nagler 1998a, b; Alvarez et al. 2000). Complete estimation results are available from the authors upon request.

Here we are concerned with the relative magnitude of each estimated issue distance parameter and the level of compactness for that issue. In Table 1 we provide the basic compactness for each issue, followed by the vote-weighted compactness in each of these 
Table 1 Compactness and issue voting

\begin{tabular}{|c|c|c|c|}
\hline Issue & $\begin{array}{c}\text { Basic } \\
\text { compactness }\end{array}$ & $\begin{array}{l}\text { Vote-weighted } \\
\text { compactness }\end{array}$ & $\begin{array}{c}\text { Conditional logit } \\
\text { estimate }\end{array}$ \\
\hline \multicolumn{4}{|l|}{ United States, 1996} \\
\hline Ideology & .53 & 1.11 & $-.44 *(.03)$ \\
\hline Government services & .59 & 1.27 & $-.29 *(.02)$ \\
\hline Defense spending & 1.02 & 2.26 & $-.18 *(.06)$ \\
\hline Government jobs & .64 & 1.33 & $-.04 \quad(.02)$ \\
\hline Aid to Blacks & .65 & 1.42 & $-.08 \quad(.02)$ \\
\hline Crime reduction & .89 & 1.82 & $.04 \quad(.02)$ \\
\hline Environmental regulation & .76 & 1.58 & $-.27 *(.03)$ \\
\hline Correlation: & .46 & .43 & \\
\hline \multicolumn{4}{|l|}{ Canada, 1993} \\
\hline Quebec & .70 & 2.09 & $-.35^{*}(.08)$ \\
\hline U.S. ties & .57 & 2.71 & $-.08 \quad(.09)$ \\
\hline Assist business & 1.07 & 5.66 & $-.21 \quad(.17)$ \\
\hline Union power & .54 & 2.51 & $-.80 *(.13)$ \\
\hline Help women & .68 & 2.98 & $-.33 *(.14)$ \\
\hline Help minorities & .73 & 2.56 & $-.59 *(.13)$ \\
\hline Correlation: & .35 & .38 & \\
\hline \multicolumn{4}{|l|}{ United Kingdom, 1987} \\
\hline Defense & .40 & 1.01 & $-.18 *(.02)$ \\
\hline Phillips curve & .59 & 1.41 & $-.11 *(.02)$ \\
\hline Taxation & .48 & 1.14 & $-.16^{*}(.02)$ \\
\hline Nationalization & .44 & 1.09 & $-.18 *(.02)$ \\
\hline Redistribution & .55 & 1.31 & $-.08 *(.02)$ \\
\hline Crime & 1.08 & 2.56 & $-.10 *(.05)$ \\
\hline Welfare & .52 & 1.21 & $-.14 *(.02)$ \\
\hline Correlation: & .60 & .58 & \\
\hline \multicolumn{4}{|l|}{ Netherlands, 1994} \\
\hline Euthanasia & .66 & .83 & $-.42 *(.06)$ \\
\hline Crime & 1.07 & 3.29 & $-.14 \quad(.11)$ \\
\hline Income differences & .50 & 1.52 & $-.41 *(.06)$ \\
\hline Nuclear plants & .74 & 1.88 & $-.17 *(.07)$ \\
\hline Ethnic minorities & .71 & 2.36 & $-.14 *(.08)$ \\
\hline European integration & 6.42 & 16.84 & $-.11 \quad(.40)$ \\
\hline Ideology & .50 & 1.40 & $-.55^{*}(.05)$ \\
\hline Correlation: & .48 & .49 & \\
\hline
\end{tabular}

*Statistically significant at the .05 level.

national elections; these are followed by the conditional logit estimate for the impact of that issue in our model of voter choice. We give the standard error of the conditional logit coefficient in parentheses and we place an asterisk next to conditional logit coefficients that are statistically significant at the .05 level. The last row of Table 1 for each nation provides the correlations between the compactness measures and conditional logit coefficients for each issue within that country. Since the coefficients on the issues are negative, we expect positive correlations between these estimated coefficients and the measures of compactness. 
Beginning with the United States, we see that the correlation between basic compactness and the conditional logit estimates for each issue is .46; the correlation for voteweighted compactness and the conditional logit estimates is a similar .43. This indicates a reasonably strong correlation between compactness and estimated impact of each issue on voter decision making, and also demonstrates that as compactness gets greater the issue has less weight in voter decisions. The same evidence is clear from direct comparison of the compactness and conditional logit estimates on an issue-by-issue basis. The issues that tend to have the lowest levels of compactness, especially ideology and government services, have the largest relative impact on voter choice and are statistically significant predictors of voter decisions. Issues with higher levels of compactness-government jobs, aid to blacks, and crime reduction-have weak and insignificant effects on voter choice. But two issues with moderate or high compactness do have significant impacts on voter decisions in the 1996 election in the United States: environmental regulation and defense spending. Yet these two more compact issues do not factor as strongly into voter choice relative to ideology and government services, the low-compactness issues in this election.

We again see a moderately strong and positive correlation between basic issue space compactness and issue voting in the 1993 Canadian election, where the correlations are .35 and .38, respectively. Again, the general pattern is consistent with our hypothesis, since as compactness increases the weight on issues in voter decision making falls. When we turn to an issue-by-issue comparison in the Canadian case, we see that all of the low compactness issues but one (the one exception being U.S. ties) have relatively strong and statistically significant impacts on voter choice in this election. The one high compactness issue, assistance to business, has a relatively slight and insignificant impact on voter choice. Thus the 1993 Canadian case provides additional support for our hypothesized relationship between issue space compactness and voter weighting of issues.

The third case in Table 1 is the United Kingdom in 1987. In this case, the correlation between both basic and vote-weighted compactness and issue weights is stronger than we saw in the U.S. or Canadian cases, being .60 or .58 in the United Kingdom. Turning to each specific issue, we once again see confirmation of our hypothesis. While all of the issues in the 1987 United Kingdom voter choice model are statistically significant, we generally see that the relative impact on voter choice of the low compactness issues is greater than the relative impact of high compactness issues. For example, the highly compact issue of crime has a conditional logit estimate of -.10 , while the issues of defense, taxation, and nationalization-which all have low compactness-have conditional logit estimates of almost twice the magnitude.

The last case we examine in this paper is the Netherlands election of 1994. Again we see positive correlations between both measures of compactness and conditional logit weights for each issue, with a correlation of .48 (basic) or .49 (vote weighted). The issueby-issue comparisons in the Netherlands 1994 election show dramatic evidence in support of our hypothesis, especially a comparison of the highly compact issues of European integration and crime with the issues that have low compactness (income differences and ideology). For both of the latter issue weight estimates, they are relatively strong and statistically significant; for both of the former issue weight estimates, they are weak and statistically insignificant. Thus the case of the 1994 Netherlands election is perfectly consistent with the three earlier cases-all provide strong and consistent support for our hypothesized relationship between issue space compactness and issue voting. In this case, moreover, we see that the vote-weighted measure is very strongly correlated with the conditional logit coefficients, making the 1994 Dutch election the best example of the utility of the vote-weighted measure of compactness. 


\section{Conclusion}

In this paper we developed new measures of the distribution of parties in issue spaces relative to voters. These measures give us important tools to assess the convergence or divergence of political parties relative to the voters on an issue-by-issue basis. In addition, because the measures compare the dispersion of the parties to the dispersion of the voters, they can be compared across issues within countries, across countries, and over time. This means that these measures have tremendous utility for comparative work, as well as for examining the evolution of party systems within countries and for studying representation. Issues that have highly compact spaces are issues on which the parties have converged in their positions relative to the range of positions held by voters; issues that have low compactness are issues on which the party positions are relatively divergent relative to the range of voters. While we have argued that our measures are fundamentally new-being the only measures we are aware of that explicitly measure the distribution of parties relative to voters-obviously it remains to be seen how they perform relative to existing measures of the distribution of parties in the issue space. The fact that our measures are fundamentally different should give leverage to future research testing what factors really do determine voters' abilities to use issues in making their vote choice. We view this as a major potential contribution of these measures.

Other than being a useful descriptive measure of the relative positioning of political parties on issues, we also hypothesized about one important implication of compactness. Following a great deal of research in political science on issue voting, we hypothesized that issues that are highly compact are ones upon which voters will not find it useful to base their decisions; thus highly compact issues ought to not be strong predictors of voter decision making. We found strong and consistent support for this hypothesis in our empirical analysis presented in the previous section of this paper.

These results therefore resonate well with much of the literature on issue voting and representation. Key (1966, p. 2) argued that "as candidates and parties clamor for attention and vie for popular support, the people's verdict can be no more than a selective reflection from among the alternatives and outlooks presented to them." If parties and candidates do not offer clear and distinct issue positions to their potential voters, it becomes quite difficult for these voters to use issue criteria in their evaluation of which party or candidate to support. This is precisely the result we see in Table 1, since as party and candidate issue positions generally become less compact (hence more distinct), the level of issue voting increases.

This research demonstrates that issues and choices matter to voters in ways consistent with theories of issue voting. While there was a longstanding debate in the political behavior literature over whether "issues mattered" (e.g., Campbell et al. 1964; Nie et al. 1979), the task in contemporary research has been to understand when issues matter more in voter choice relative to other factors (for example, economic factors) as well as why it is that some issues are stronger predictors of voter choices than other issues (Alvarez and Nagler 1995, 1998b). Our examination of issue space compactness has given us a way to directly test hypotheses about how relative party positioning affects voters' abilities to use issues in their voting decisions. The results we have presented above demonstrate that one important determinant of issue effects in elections is the relative convergence or divergence of parties relative to voter distribution on issues. Thus the context of party strategic positioning in elections matters, by influencing which issues voters find useful in their deliberations. The methodology developed also offers a means of comparing party systems across countries, and over time within individual countries. 


\section{References}

Aldrich, J. H., and R. D. McKelvey. 1977. "A Method of Scaling with Applications to the 1968 and 1972 Presidential Elections." American Political Science Review 71:111-130.

Alvarez, R. M. 1998. Information and Elections, Revised to Include the 1996 Presidential Election. Ann Arbor: University of Michigan Press.

Alvarez, R. M., C. H. Franklin. 1994. "Uncertainty and Political Perceptions." Journal of Politics 56: 671-689.

Alvarez, R. M., and J. Nagler. 1995. "Economics, Issues and the Perot Candidacy: Voter Choice in the 1992 Presidential Election." American Journal of Political Science 39:714-744.

Alvarez, R. M., J. Nagler. 1998a. "Economics, Entitlements and Social Issues: Voter Choice in the 1996 Presidential Election." American Journal of Political Science 42:1349-1363.

Alvarez, R. M., J. Nagler. 1998b. "When Politics and Models Collide: Estimating Models of Multiparty Elections." American Journal of Political Science 42:55-96.

Alvarez, R. M., J. Nagler, J. Willette. 2000. "Measuring the Relative Impact of Issues and the Economy in Democratic Elections." Electoral Studies 19:237-253.

Anker, H., E. V. Oppenhuis. 1997. Dutch Parliamentary Election Study, 1994. [Computer file]. Amsterdam: Dutch Electoral Research Foundation and (SKON)/Netherlands Central Bureau of Statistics (CBS) [producers], 1995. Amsterdam: Steinmetz Archive/Ann Arbor: Inter-university Consortium for Political and Social Research [distributor], 1997.

Bartels, L. M. 1986. "Issue Voting Under Uncertainty: An Empirical Test." American Journal of Political Science 30:709-728.

Bartolini, S., P. Mair. 1990. Identity, Competition, and Electoral Availability: The Stabilization of European Electorates 1885-1985. New York: Cambridge University Press.

Brady, H. E., S. Ansolabehere. 1989. "The Nature of Utility Functions in Mass Publics." American Political Science Review 83:1165-1179.

Budge, I., D. Robertson, and D. Hearl, eds. 1987. Ideology, Strategy and Party Change: Spatial Analyses of Postwar Election Programmes in 19 Democracies. New York: Cambridge University Press.

Campbell, A., P. E. Converse, W. E. Miller, D. E. Stokes. 1964. The American Voter. New York: Wiley.

Castles, F., and P. Mair. 1984. "Left-Right Political Scales: Some 'Expert' Judgements." European Journal of Political Research 12:73-88.

Davis, O. A., M. J. Hinich. 1966. "A Model of Policy Formation in Democratic Society." In Mathematical Applications in the Social Sciences, ed. J. L. Bernd. Dallas: Southern Methodist University Press, pp. 175-208.

Davis, O. A., and M. J. Hinich, P. Ordeshook. 1970. “An Expository Development of a Mathematical Model of the Electoral Process." American Political Science Review 64:426-448.

Downs, A. 1957. An Economic Theory of Democracy. New York: Harper and Row.

Enelow, J., M. Hinich. 1984. The Spatial Theory of Voting. Cambridge: Cambridge University Press.

Franklin, C. H. 1991. "Eschewing Obfuscation? Campaigns and the Perceptions of U.S. Senate Incumbents." American Political Science Review 85:1193-1214.

Gabel, Matthew J., and John Huber. 2000. "Putting Parties in Their Place: Inferring Party Left-Right Ideological Positions from Party Manifestos Data.” American Journal of Political Science 44:94-103.

Heath, A., R. Jowell, and J. K. Curtice. 1995. British Election Study: Cross-Section 1987. [Computer file]. London: Social and Community Planning Research/Oxford: A. Heath et al., Oxford University [producers], 1989. Colchester, England: ESRC Data Archive/Ann Arbor: Inter-university Consortium for Political and Social Science Research [distributor], 1995.

Holland, Paul W., and Howard Wainer, eds. 1993. Differential Item Functioning. Hillsdale, NJ: Erlbaum Associates.

Johnston, R., and A. Blais, H. Brady, E. Gidengil, N. Nevitte. 1995. Canadian Election Study, 1993: Incorporating the 1992 Referendum Survey on the Charlottetown Accord. [Computer file]. ICPSR version. Vancouver: Richard Johnston, University of British Columbia/Montreal: Andre Blais, University of Montreal/ Berkeley, CA: Henry Brady, University of California/Montreal: Elisabeth Gidengil, McGill University/ Calgary, Alberta: Neil Nevitte, University of Calgary [producers], 1995. Ann Arbor: Inter-university Consortium for Political and Social Research [distributor], 1995.

Key, V. O. 1966. The Responsible Electorate. New York: Vintage.

Kim, Hee-min, Richard C. Fording. 2002. "Extending Party Estimates to Governments and Electors." In Mapping Policy Preferences, eds. Ian Budge et al. New York: Oxford University Press, pp. 157-178.

King, Gary, Christopher J. L. Murray, Joshua A. Salomon, Ajay Tandon. 2003. "Enhancing the Validity and Cross-Cultural Comparability of Measurement in Survey Research." Unpublished manuscript, Harvard University. 
Klingemann, Hans-Dieter. 1995. "Party Positions and Voter Orientations." In Citizens and the State, eds. HansDieter Klingemann and Dieter Fuchs. New York: Oxford University Press, pp. 183-205.

Klingemann, Hans-Dieter, Bernhard Wessels. 2002. "Sincere Voting in Different Electoral Systems." Unpublished manuscript, Wissenschaftzentrum Berlin fur Sozialforschung.

Laver, Michael, and Kenneth Benoit, John Garry. 2003. "Extracting Policy Positions from Political Texts Using Words as Data." American Political Science Review 97:311-331.

Laver, M., and W. B. Hunt. 1992. Policy and Party Competition. New York: Routledge.

Mair, P. 1996. "Party Systems and Structures of Competition." In Comparing Democracies: Elections and Voting in Global Perspective, eds. L. LeDuc, R. G. Niemi, and P. Norris. Thousand Oaks, CA: Sage, pp. 83106.

Nie, N. H., S. Verba, and J. R. Petrocik. 1979. The Changing American Voter. Cambridge, MA: Harvard University Press.

Page, B. I. 1976. "The Theory of Political Ambiguity." American Political Science Review 70:742-52.

Page, B. I. 1978. Choices and Echoes in Presidential Elections. Chicago, IL: University of Chicago Press.

Page, B. I., and R. A. Brody. 1972. "Policy Voting and the Electoral Process: The Vietnam War Issue." American Political Science Review 66:979-995.

Palfrey, T. R., K. T. Poole. 1987. "The Relationship between Information, Ideology, and Voting Behavior." American Journal of Political Science 31:511-530.

Poole, K. 1998. "Recovering a Basic Space From a Set of Issue Scales.” American Journal of Political Science 42:954-993.

Rosenstone, S. J., D. R. Kinder, W. E. Miller, and the National Election Studies. 2000. American National Election Study, 1996: Pre- and Post-Election Survey. [Computer file]. 4th version. Ann Arbor: University of Michigan, Center for Political Studies [producer], 1999. Ann Arbor: Inter-university Consortium for Political and Social Research [distributor], 2000.

Sani, G., G. Sartori. 1983. "Polarization, Fragmentation and Competition in Western Democracies." In Western European Party Systems: Continuity and Change, eds. H. Daalder and P. Mair. Beverly Hills, CA: Sage, pp. 307-340.

Sartori, G. 1976. Parties and Party Systems: A Framework for Analysis. New York: Cambridge University Press.

Shepsle, K. A. 1972. "The Strategy of Ambiguity: Uncertainty and Electoral Competition." American Political Science Review 66:555-568.

Van Der Eijk, C. 2001. "Measuring Agreement in Ordered Rating Scales." Quality and Quantity 35:325-341.

Ware, A. 1996. Political Parties and Party Systems. New York: Oxford University Press. 